\section{Primary Amoebic Meningoencephalitis}

Until recently Entamoeba histolytica has been regarded as the only important amoeba pathogenic to man, though several other species can be parasitic without causing symptoms. ${ }^{1}$ There are many species of free-living amoebae, which generally inhabit the soil or stagnant water and flourish in warm climates. C. G. Culbertson and colleagues ${ }^{2}$ found that species in one genus, Hartmanella, caused fatal lesions of the brain and spinal cord in laboratory animals and later confirmed ${ }^{3}$ the pathogenicity of this organism to mammals.

Soon it became apparent that free-living amoebae could also affect man. The first report of a case came from Australia, where M. Fowler and R. F. Carter ${ }^{4}$ described four fatal cases of acute pyogenic meningitis in which amoebae morphologically identical with the Hartmanella were identified post mortem. Further reports followed from the southern states of the U.S.A., Australia, New Zealand, and Czechoslovakia. The invading organism was cultured from cerebrospinal fluid in four cases, either during life or post mortem. In one non-fatal case $^{5}$ it was Acanthamoeba (syn. Hartmanella) astronyx, the pathogenic role of which has been disputed ${ }^{16}$; in the three fatal cases ${ }^{5} 78$ it was another species of free-living amoeba, Naegleria. Differentiation of these genera may be difficult in histological preparations, for in stained sections they may appear as no more than smudges. ${ }^{1}$ Naegleria, however, has smaller trophozoites than Hartmanella, and a flagellate phase can be induced in culture by exposing the organism to distilled water. ${ }^{9}$

The epidemiology and pathology of primary amoebic meningoencephalitis has recently been reviewed by W. St.C. Symmers ${ }^{1}$ and by R. J. Duma and colleagues. ${ }^{6}$ The patients affected were mainly children and young adults who had been swimming in inland water during hot weather. The only notable exceptions were in winter outbreaks in Czechoslovakia, ${ }^{10}$ where the victims had swum in a heated indoor pool, and in New Zealand, ${ }^{11}$ where they had bathed in hot mineral springs. The infection of the olfactory lobes of the brain, together with the concurrent inflammation and ulceration of the nasal mucosa and the identification of amoebae in the mucosal exudate, points to the cribriform plate as the most likely portal

1 Symmers, W. St.C., British Medical fournal, 1969, 4, 449.

2 Culbertson, C. G., Smith, J. W., Cohen, H. K., and Minner, J. R., American fournal of Pathology, 1959, 35, 185.

3 Culbertson, C. G., American fournal of Clinical Pathology, 1961, 35, 195.

4 Fowler, M., and Carter, R. F., British Medical fournal, 1965, 2, 740.

5 Callicott, J. H., jnr., et al., fournal of the American Medical Association, 1968, 206, 579.

6 Duma, R. J., Ferrell, H. W., Nelson, E. C., and Jones, M. M., New England fournal of Medicine, 1969, 281, 1315.

7 Carter, R. F., fournal of Pathology and Bacteriology, 1968, 96, 1.

8 Butt, C. G., Baro, C., and Knorr, R. W., American fournal of Clinical Pathology, 1968, 50, 568

9 Culbertson, C. G., Ensminger, P. W., and Overton, W. M., fournal of Protozoology, 1968, 15, 353.

10 Cerva, L., Novák, K., and Culbertson, C. G., American Fournal of Epidemiology, 1968, 88, 436.

11 New Zealand Medical fournal, 1969, 69, 164.

12 The Times, 13 August 1969, p. 1.

13 Carter, R. F., Fournal of Clinical Pathology, 1969, 22, 470.

14 Culbertson, C. G., Holmes, D. H., and Overton, W. M., American Fournal of Clinical Pathology, 1965, 43, 361.

15 Chang, S. L., fournal of General Microbiology, 1958, 18, 565. of entry, ${ }^{7}$ and this is consistent with the history of swimming and diving in contaminated water. All but one of the patients so far reported on died after a fulminating attack of purulent meningitis which resisted conventional chemotherapy. The sole exception was a patient in whom a Hartmanella-possibly a contaminant-was cultured from the cerebrospinal fluid. ${ }^{5}$

In his detailed review Symmers ${ }^{1}$ produced evidence that primary amoebic meningoencephalitis might have occurred in Great Britain and Northern Ireland. As he freely admitted, neither of the patients he described was adequately documented, but he emphasized the reasons why the diagnosis might easily be overlooked and urged that it should be considered in cases of purulent meningitis not responding to therapy. His suspicions were soon to be realized, ${ }^{12}$ and at page 596 this week we publish an account by Dr. J. Apley and his colleagues of a fatal case occurring in Bristol, together with a probable further case which ended in recovery after treatment with amphotericin B and a third case treated as suspected. The story was nearly typical. The deceased boy and his brother were too young to swim but had splashed about in a muddy puddle which formed in their garden after a thunderstorm during an unusually prolonged hot spell in August 1969. The clinical picture was that of a boy with meningitis, not responding to treatment with sulphadiazine, penicillin, and ampicillin, and rapidly deteriorating. The cerebrospinal fluid was thickly purulent and contained numerous red blood cells, which is also characteristic. ${ }^{56}$ Amoebae were cultured and identified as Naegleria sp. Though the boy died despite treatment with amphotericin B, to which R. F. Carter ${ }^{13}$ had previously demonstrated sensitivity of this organism, the cerebrospinal fluid had been cleared of amoebae before death. The boy's brother, who developed a similar illness, was treated promptly, on the suspicion that he might have the same infection, and recovered. Though naegleriae were not seen in wet preparations, they were isolated from the cerebrospinal fluid by culture.

Clearly the diagnosis of primary amoebic meningoencephalitis should be considered when the response to conventional chemotherapy is unsatisfactory and deterioration is occurring. Indeed this may be too late. It is better to consider it on admission, for amoebae can readily be distinguished from leucocytes provided wet preparations are examined with care. The trophozoite has a single nucleus containing a conspicuous karyosome, shows characteristic pseudopodia, and may have ingested erythrocytes. The appearance has been well illustrated in colour. ${ }^{6}$ But it is necessary to examine the cerebrospinal fluid while still warm, or with a warm-stage microscope, since cooling reduces motility. ${ }^{1}$ Moreover, it requires $30-45$ seconds' observation of individual cells to detect alterations in shape, as Apley and his colleagues point out.

From the available evidence it seems that Naegleria is the only free-living amoeba with undoubted pathogenicity in man, and amphotericin B should be regarded as the treatment of choice. However, in view of the suggestion that Hartmanella may have caused infection, sulphadiazine should also be given. ${ }^{14}$ Even in the British Isles the summer temperatures may unexpectedly rise to levels which favour proliferation of these amoebae, ${ }^{1}$ and since by encystment they can endure freezing temperatures for long periods ${ }^{15}$ it is a reasonable assumption that they may survive our winters. The papers by Symmers and Apley and colleagues have served a useful purpose in drawing our attention to the existence of these free-living but pathogenic amoebae as residents, and not just occasional visitors from overseas. 